\title{
Do que pode constituir marca de indústria e de comércio. Sua aposição aos produtos e mercadorias
}

(Ponto número 2)

\section{Ernesto de Moraes Leme}

Os industriais e comerciantes, cujos produtos, pela sua excelência, conseguiram acreditar-se, teem interesse em distinguí-los, de qualquer fórma, dos congêneres, para se garantirem a preferência, por parte dos consumidores. Isso conseguem mediante a aposição de marcas distintivas, nos próprios produtos, ou em seus envoltórios. Tais marcas distintivas é que se chamam - marcas de fábrica, ou, mais propriamente, marcas de indústria e de comércio. A sua definição decorre do seu próprio cônceito, que aí fica expresso: marca de indústria e de comércio é "tudo aquilo que a lei não proíba e faça diferençar o objeto de outros idênticos ou similhantes, de proveniência diversa, ainda mesmo qualquer nome, denominação necessária ou vulgar, firma ou razão social, letra ou cifra, contanto que revistam fórma distintiva" E', aliás, a definição que se encontra no art. 19, do Regulamento que baixou com o decreto n. 5.424, de 10 de janeiro de 1905, regulamento esse expedido nos termos da lei n. 1.236, de 24 de setembro de 1904 .

Usadas, a princípio, tamsómente para indicar os fabricantes dos produtos expostos à venda, de onde a expressão marcas de fábrica, passaram, depois, a ser utilizadas tam- 
bem pelos comerciantes, nos produtos objetos de negociação em seus estabelecimentos. A fórmula - marcas de indústria $e$ de comércio - é, de tal maneira, mais própria, porque mais compreensiva.

Entre nós, as marcas de indústria e de comércio, regidas pelo decreto n. 3346 , de 14 de outubro de 1887, passaram depois a obedecer às prescrições da lei n. 1236, de 24 de setembro de 1904, regulamentada pelo decreto n. 5.424, de 10 de janeiro de 1905. Criada a Diretoria Geral de Propriedade Industrial, pelo decreto n. 16.264, de 19 de dezembro de 1923, foram reorganizados os serviços de patentes de invenção e marcas de indústria e comércio, pelo regulamento que baixou com esse mesmo decreto. Essa Diretoria passou, após, a se denominar Departamento Nacional da Propriedade Industrial, a que o decreto n. 22.989, de 26 de julho de 1933, deu novo regulamento. E o decreto n. 22.990, dessa mesma data, modificou algumas disposições do regulamento de 1923, em referência ás patentes de invenção e marcas de indústria e de comércio.

Em face da nossa lei, a marca pode consistir em qualquer palavra, denominação necessária ou vulgar, firma ou razão social, letra ou algarismo. Basta que revistam uma "fórma distintiva" Como tambem pode ser qualquer desenho, ou alegoria, que se refiram, em seus traços, à mercadoria que visam caracterizar. No primeiro caso, teremos a marca nominal; no segundo, a emblemática.

Tratando-se de marca nominal, é mistér que a mesma tenha veracidade. Não é possivel, por exemplo, à firma Martins Costa \& Cia., distinguir os seus produtos com a razão social J. Moreira \& Cia. O mesmo, já ficou escrito, diremos em relação às marcas emblemáticas, que devem ter relação com os produtos a que serão apostas.

As marcas pódem ser, ainda simples, complexas ou mixtas. São simples as que, decompostas em seus elementos, compõem-se de traços ou indicações sem característico especial. Complexas as que, com essa decomposição, for- 
mam em seus elementos componentes, outras marcas especiais. As marcas complexas são tambem chamadas mistas. Pelo art. 87 do regulamento de 1923, "é permitido aos sindicatos ou coletividades industriais ou mercantis o uso de marcas que assinalem e distingam os produtos de sua fabricação ou comércio, desde que para esse efeito se sujeitem às prescrições e formalidades estabelecidas neste regulamento" São as chamadas marcas coletivas. Tambem se vem usando, nos últimos tempos, caracterizarem os operários de uma certa fábrica os produtos para cuja feitura concorreram, mediante uma marca própria, que se diz - marca de trabalho.

Os comerciantes e industriais ingleses usam tambem registar as marcas em série, isto é, marcas que conteem, apenas, uma variante mínima, e que se destinam a distinguir os vários produtos de sua fabricação. Tem esse registo vantagens evidentes.

Tambem podem os comerciantes e industriais registar outras marcas atinentes à marca, ou marcas de seu uso, para evitar que algum interessado delas venha a se servir. E' o que se chama - marca de defesa. Mas, essa medida, de simples cautela, torna-se desnecessária, com o cumprimento sevéro da lei: porque a ninguem é lícito registar uma marca que possa trazer, ao público desavisado, confusão com qualquer outra. O Departamento, quando se tratar do registo, o juiz, quando se tratar de processo a tais marcas referente, teem de se colocar na posição de pessoa do vulgo em face de uma só de tais marcas, sem ter à sua frente a outra, para cotejar. E' possivel confusão entre elas? O registo de tal marca não é possivel, a sua anulação é de se decretar.

$\mathrm{O}$ registo das marcas é facultativo. A lei n. 1.236, de 24 de setembro de 1904, dí-lo, expressamente, em seu art. $1 .^{\circ}$ : "O industrial ou negociante tem o direito de assinalar as suas mercadorias ou produtos por meio de marcas especiais" O regulamento que baixou com o decreto n. 16.264, de 19 de dezembro de 1923, art. 78: "Será garantido o uso exclusivo da marca de indústria ou de comércio ao indus- 
trial ou comerciante que a fizer registar de acôrdo com o presente regulamento."

A' primeira vista, parece que a lei impõe a obrigatoriedade do uso de marcas, quando determina, no decreto $\mathrm{n}$. 452 , de 30 de novembro de 1897 , que os preparados farmaceuticos devem ter, forçadamente, a declaração do nome do fabricante, do produto e do logar da procedência; quando manda que os produtos nacionais contenham o nome do fabricante, da fábrica e da localidade desta, ou a declaração - Indústria Nacional, sendo essa formalidade cumprida, quando se tratar de fazendas, além do mais, com as côres nacionais, apostas no ourelo; tambem não sai uma saca de café do país sem levar a designação da procedência, com as côres nacionais, ou a bandeira nacional, nas sacarias. Tais exigências da lei, contudo, ditadas pela necessidade da defesa do comércio nacional ou da saúde pública, não se referem a marcas particulares, com que o comerciante, ou industrial, destaca as suas mercadorias das of erecidas ao público, ou fabricadas, por outro industrial ou comerciante.

Dissemos que a marca pode consistir, nos termos do regulamento de 1923, art. 79, em "qualquer palavra, denominação necessária ou vulgar, firma ou razão social, letra ou algarismo". Devem, todavia, revestir "fórma distintiva"

Entre a marca de indústria e comércio e a firma ou razão social, bem como entre ambas e a insígnia, ha diferenças palpáveis, que é mistér esclarecer. Tanto a insígnia, como a firma, podem constituir marca de indústria e comércio. E' mistér para isso, entretanto, que adotem o característico exigido pela lei. A insígnia, ou taboleta, ou nome pelo qual se distingue o estabelecimento, serve para marcar a casa de comércio. A firma, ou razão social, para distinguir o comerciante. A marca, para caracterizar o produto.

Os recipientes, ou envólucros, podem, tambem, ser objeto de marca. Para isso, entanto, forçoso é que do comum dos envólucros e recipientes se distingam, pela originalidade de sua feitura. Assim a fórma e a côr dos produtos. Mas, será possivel a alguem obter côr e fórma ainda não conhecidas? 
Não, quiçá, com os recursos atuais da ciência e da indústria. Mas, o mundo, dia a dia, nos reserva tantas surprezas!

Para bem compreendermos o que, em face da lei, póde constituir marca de indústria e comércio, é preciso que tambem vejamos o que não pode ser objeto desse privilégio. E' matéria de que cogita o art. 80 do Regulamento de 1923 e da qual faziam menção os dispositivos anteriores, (dec. n. 5.424, de 10 de janeiro de 1905, art. 21; lei n. 1.236, de 24 de setembro de 1904 , art. $\left.8 .^{\circ}\right)$ :

I, armas, brasões, medalhas ou distintivos públicos ou oficiais, nacionais ou estrangeiros, quando para seu uso não tenha havido autorização competente;

II, o emblema da Cruz Vermelha, bem como as palavras "Cruz Vermelha" e "Cruz de Genebra";

III, nome comercial, ou razão social, de que o comerciante, ou industrial não possa usar, legitimamente;

IV, indicação da localidade ou estabelecimento, que não seja da proveniência do produto, ou artigo, quer a essa indicação se junte um nome suposto ou alheio, quer não;

$\mathrm{V}$, palavras, imagens, ou representação, envolvendo ofensa individual, ou ao decôro público;

VI, reprodução de outra marca já registada para produtos ou artigos da mesma classe;

VII, imitação, total ou parcial de marca já registada, para produto ou artigo da mesma classe, que possa induzir o comprador a êrro, ou confusão, dando-se a possibilidade do êrro, ou confusão uma vez que as diferenças entre as marcas não possam ser reconhecidas, sem exame ou confrontação;

VIII, medalhas de fantasia suscetíveis de confusão, com as concedidas em exposições industriais;

IX, nome patronímico de terceiros, sem o consentimento expresso destes;

$\mathrm{X}$, nome de um logar para designar a fabricação ou proveniência de um produto, nascido ou fabricado em outro; 
XI, desenhos litografados, gravados ou suscetíveis de reprodução por qualquer sistema, uma vez registados, nos termos do art. 673 do Código Civil;

XII, reprodução de retratos ou bustos, sem consentimento expresso da pessoa representada, seus herdeiros ou sucessores.

A lei não permite, outrossim, o registo de marca de produtos nacionais com os dizeres, ou rótulos, em lingua estrangeira. Excetua, porém, o caso de bebidas que não teem nomes correspondentes em português, como: bitter, brandy, cognac, fernet, kirsch, rhum, assim como o de serem estrangeiros os nomes do autor, fabricante, ou inventor.

Essas restrições legais teem a sua explicação nos interesses internacionais, nacionais, ou particulares em jôgo. E' o caso do emblema da Cruz Vermelha, ou das palavras "Cruz Vermelha", ou "Cruz de Genebra", que as convenções entre os diversos paizes reservam para os serviços de socôrro que essa entidade presta, em caso de guerra. E' o do uso de nomes alheios, comerciais ou patronímicos, bem como o da reprodução de retratos ou bustos, de quem quer que seja. E' o da utilização de palavras, imagens, ou alegorias imorais. E' o da reprodução, ou imitação de marca já registada.

$\mathrm{O}$ art. 80, n. I, do Regulamento, tambem se refere a $a r-$ mas e brasões, "quando para seu uso não tenha havido autorização competente" E' reprodução do preceito que vinha das leis anteriores, desde o tempo da Monarquia.

Será o caso de algum estrangeiro, industrial ou comerciante, que goze de fóros de nobreza e queira, em sua marca, reproduzir o distintivo de sua estirpe ou de seu grau? E' provavel. Porque, quanto aos negociantes brasileiros, tal não seria possivel. Nos termos do art. $72, \S 2 .^{\circ}$, da Constituição Federal, não admitindo a República privilẻgios de nascimento, desconhecendo fóros de nobreza, extinguiu "as ordens honoríficas existentes e todas as suas prerrogativas e regalias, bem como os títulos nobíliárquicos e de conseIho" 
Entre as marcas que não admitem reprodução, ou imitação, estão as que gozam de proteção internacional, por serem registadas em Berna.

Tambem não pódem ser objeto de marca, para gozar da proteção estatuida em lei, as expressões comuns, ou vulgares, como agulha, enxada, caneta.

Vimos, até aqui, o que pode constituir marca de indústria e de comércio. Passemos à segunda parte do ponto: sua aposição aos produtos e mercadorias.

A utilização das marcas, nos produtos e mercadorias, pode revestir-se das fórmas, as mais diversas.

Tanto pode a aposição ser feita nos próprios efeitos, como em seus envólucros, ou recipientes. Numa peça de fazenda, pode-se colocar a marca no próprio produto. Mas, o fabricante de linhas ha de apôr a sua marca nos carreteis, nas caixas, ou nos caixotes.

Tanto póde, outrossim, ser a marca estampada diretamente na mercadoria, como impressa, ou litografada em papel, ou cartão, que se pregam nas faculdades. A estampa será objeto, tambem, dos processos mais variados de impressão: a comum reprodução das tipografias, ou a pirogravura.

Para o registo das marcas, os clichés, ou desenhos, devem obedecer às dimensões expressas no regulamento: 7 centimetros por 10, para os primeiros, 33 centimetros por 22, para os segundos. A lei não prescreveu, contudo, dimensões especiais, em sua aposição aos produtos e mercadorias.

São estas, eminente Comissão Examinadora, as observações que nos sugere a tese proposta. Restrita, por essência, não dá logar a maiores explanações a respeito. Ao menos para os apoucados conhecimentos do candidato. 
Não encerraremos esta prova, todavia, sem dizermos que podem ser usadas marcas tanto para os produtos materiais, como intelectuais, ou artísticos. Que é o nome de jornal, senão uma marca, com que se visa distinguir a produção espiritual do grupo que o compõe? Que são os $e x$ libris, com que alguns autores publicam as suas obras, senão marcas, que eles apõem, para bem caracterizá-las?

E' certo que não conhecemos ex libris devidamente registados, para valerem como marca, na Repartição competente. Mas, estejamos certos, o primeiro exemplo não ha de tardar.

Faculdade de Direito de S. Paulo, aos 16 de agosto de 1933. 